\title{
The contribution of distributed flexibility potentials to corrective transmission system operation for strongly renewable energy systems
}

Till Kolster ${ }^{a, b} *$, Rainer Krebs ${ }^{a, c}$, Stefan Niessen ${ }^{a, b}$, Mathias Duckheim $^{a}$

aSiemens AG, Guenther-Scharowsky-Str. 1, 91058 Erlangen, Germany

bDepartment of Electrical Engineering and Information Technology, Technical University of Darmstadt, Fraunhoferstr. 4, 64283 Darmstadt

'Institut für Elektrische Energiesysteme (IESY), Otto-von-Guericke-Universität Magdeburg, Universitätsplatz 2, 39106 Magdeburg

Corrective operation of electrical transmission systems requires flexibility degrees of freedom to be reliably available when the system is in a critical state. In this study, we develop a method to quantify flexibility potentials from distributed and sector-coupling energy resources. We develop key performance indicators (KPIs) that correlate these potentials with the occurrence of critical transmission corridor loadings and, by that, quantify how often flexibility degrees of freedom are available when they are required.

The method is tested on the example of Germany embedded in a central European energy system in the year 2030. In the considered strongly renewable scenario (208GW installed renewable capacity) the supply often exceeds the demand. This leads to large-scale curtailments that can be used as a source for flexibility, particularly flexibility to re-increase generation. We find that, in total, curtailed onshore wind parks in the $110 \mathrm{kV}$-systems would have the potential to increase their feed-in power by $5 \mathrm{GW}$ (upward flexibility) in the $10 \%$ most critical transmission scenarios. Central power-to-heat (P2H) plants can provide their total power of $16.1 \mathrm{GW}$ upward flexibility potential in these scenarios.

Analyzing each transmission corridor separately, we find that corrective setpoint adjustments from the same technology combination, wind and $\mathrm{P} 2 \mathrm{H}$, can completely compensate a sudden loss of $2 \mathrm{GW}$ transmission capacity for up to $40 \%$ of critical timesteps on the transmission corridors within the given model. These findings indicate that flexibility from sector-coupling elements and decentral energy resources are a relevant resource and can be applied for corrective actions in transmission system operations. 


\section{Introduction}

As the transmission demands on electricity grids increase along with increasing installed renewable capacities and grid expansion plans are delayed throughout Europe [1], [2], grid operators investigate alternative grid operation strategies that complement grid expansion with methods to achieve higher utilization of the existing system. In this context, corrective system operation approaches are investigated [3], [4]. At least since 2009, the ENTSO-E also includes curative remedial action schemes in their operation handbook [5], defining them as “... those [actions] needed to cope with and to relieve rapidly constraints with an implementation delay of time for full effectiveness compatible with the Temporary Admissible Transmission Loading. They are implemented after the occurrence of the contingencies." In North America, the NERC defines general operation and reliability guidelines [6], also including remedial action schemes to maintain system stability after a tripping event [7]. Due to the lack of a central grid planning and expansion agency in the USA and Canada, delays and expansion of the transmission grid are not comprehensively compiled. Nevertheless, renewable energy integration is also considered to be delayed by lagging grid expansion and maintenance [8][10]. While currently, most transmission networks are operated preventively n-1-safe, such that upon the failure of an asset a safe system state emerges without intervention, in corrective operation, such a contingency is compensated by fast measures to reestablish a permanently safe state. Corrective operation approaches rely on the fact that remaining assets can temporarily be subject to higher loading (utilizing thermal inertia) and that a safety-establishing measure can be implemented reliably and sufficiently fast. By reserving smaller safety margins preventively, corrective operation approaches are expected to enable higher grid utilization and achieve lower system costs at a price of higher transmission losses. However, they must be carefully integrated into the existing system operation concepts and remain to prove that these expectations are fulfilled under real-life conditions with forecasting uncertainty, system stability, and system protection requirements.

To develop such innovative operation strategies with the objective of achieving a higher system utilization, particularly, corrective operation approaches, a consortium has formed in the InnoSys2030 research project [11]. In InnoSys, several degrees of freedom are considered for use as corrective measures, e.g., grid-boosters, topological switching, corrective setpoint adjustments of high-voltage DC (HVDC) lines and phase-shifting transformers (PSTs).

A degree of freedom that is expected to grow in relevance, as more renewable and sectorcoupling energy resources are installed in lower voltage levels, is flexibility from distribution and sub-transmission systems. In these grid levels, distributed energy resources can vary their power generation or consumption upon a control command, thereby offering flexibility to system operators. As a corrective measure, the system operator adjusts the power output of the energy resource in a contingency to reestablish a safe system state. However, to understand the practical feasibility of such an approach it is important to know how large this flexibility potential is and if it is available at times when the grid operator needs it, otherwise it does not justify a corrective grid operation. To evaluate the availability of such flexibility, it is essential to know not only how many flexible assets there are, but also how they are operated in a future energy system when its grid is in a critical state. A simple schematic of the concept is shown in Figure 1, where flexibility in two neighboring regions is 

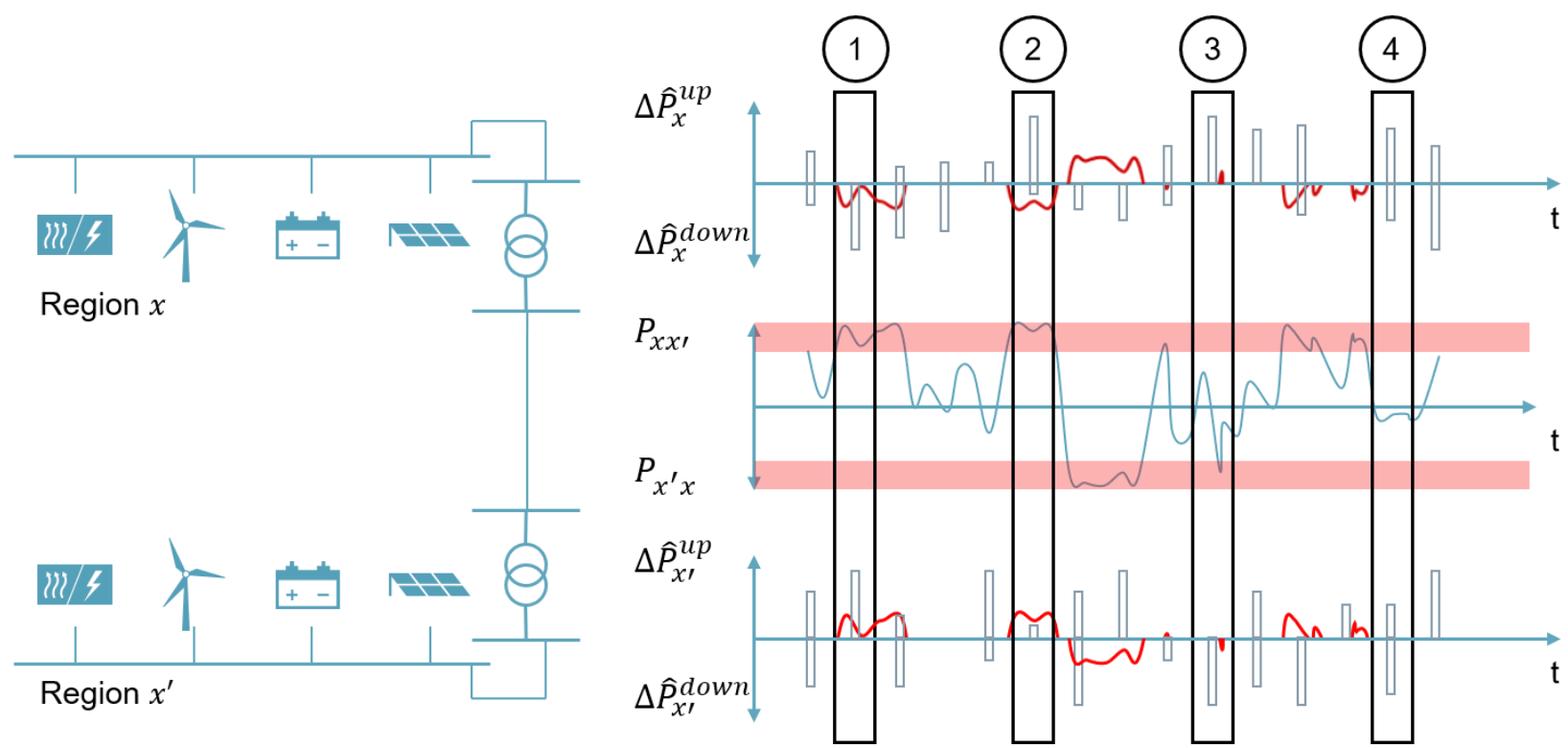

Figure 1: Concept of flexibility from sub-transmission grids for use in a corrective transmission system operation. Left panel: schematic representation of region $x$ and $x$ ' connected by a transmission line $x x^{\prime}$. Icons (PV panel, battery, wind power plant, $\mathrm{P} 2 \mathrm{H}$ plant) represent distributed energy resources in the connected distribution systems. Right panel: Upward and downward flexibility potentials of Regions $x$ and $x^{\prime}$ are plotted above and below the utilization $P_{x x^{\prime}}$ of the connecting transmission corridor. Intervals of critically high utilization are shown as light red bands. Sections of $P_{x x^{\prime}}$ within the critical intervals are also re-plotted as red traces in the top and bottom panels to allow for better comparison to the available flexibility potential. Four cases are shown. In case 1, there is enough flexibility to allow corrective operation in a critical timestep. In case 2, flexibility is available but not enough to allow corrective operation (see red lines). In case 3 , the power-flow is in the opposite direction from $x^{\prime}$ to $x$ and enough flexibility potential is available, like in the first case but with opposite signs. In case 4 flexibility is available but not needed.

used to allow for corrective operation of their connecting transmission-grid corridor.

The contribution of this paper is a method to calculate if and when distributed and sectorcoupling flexibility potentials are of value for corrective system operation. On the one hand, we quantify the time-varying, spatial distribution of flexibility potentials whose magnitude depends strongly on the technology scenario, the demand and the asset operation schedules. On the other hand, we correlate these potentials with the state of transmission corridors. To achieve this, we endogenously model curtailed renewables, storages, and central power-to-heat assets in regional and hourly resolution. By quantifying the simultaneity of regionalized flexibility demand and availability, we address the question whether flexibility is available when and where it is required, i.e., in regions adjacent to critical transmission corridors. We analyze flexibility specifically for individual transmission corridors assuming a corrective transmission system operation and determine its benefit for a corrective energy system operation.

In this paper, we introduce this newly developed method and, with its help, analyze the flexibility potential from assets in distribution systems on the example of a strongly renewable scenario in a correctively operated transmission system in Germany with $208 \mathrm{GW}$ of installed wind and photovoltaic capacity which corresponds to the NEP2030c (2019) scenario [12]. An energy system model of this scenario was implemented in the Energy System Development Plan [13] (ESDP). With the objective to decarbonize the energy system at minimum overall costs, ESDP optimizes investments and hourly dispatches, includes CO2-emissions models and limits, spatial resolution, and a transmission capacity model, where optimally controlled DC-links represent 
transmission capacities between regions. This enables us to identify both bottlenecks and timesteps where flexibility is needed in a sectorcoupled model. The method described here can be applied not only to the German energy system, but to any that faces the same challenges, namely increasing, non-equally distributed renewable energy integration, stressing existing transmission grids.

Previously, aspects of distribution system flexibility have been investigated by several research projects, e.g. SysDL2.0, REGEES, EUSysFlex, IMOWEN, Interplan, DA/RE, and enera [14]-[20]. A large set of these works assumes a given set of flexible assets in the distribution system with given flexibility ranges. The utilization of these flexibility ranges requires DSOs and TSOs to agree on how to integrate flexibility into their system operation concepts [20], [21]. For the TSO to avoid handling a prohibitively large number of individual flexible assets, (hierarchical) aggregation approaches are developed and formulated as mathematical optimization problems for flexibility provision [20]-[24]. Additional contributions develop coordination strategies, e.g. assigning access rights for flexible assets [21], [25], [26] between system operators, or investigate how to incentivize market participants to offer flexibility [27], [28]. Other works investigate which sources are best suited to provide flexibility [29], [30] and optimize flexibility ranges of plants in the grid, or propose ways for cooperation between TSOs and DSOs [22], [31], [32].

A second set of works focuses on explicitly quantifying flexibility potentials. A range of works focuses on demand-side management (DSM) by industrial processes [33]-[35] or households [35], some are also approximating these potentials for future scenarios [36], [37]. These approaches and several more listed in [21] use market and regulatory data such as [38] to derive estimates for the potentials based on currently installed renewable capacities. On the example of Germany, in [21], averages over potentials from the analyzed studies are calculated and amount 10.8GW (median) or 18.7GW (mean), of which 3.8GW (median) or $5.9 \mathrm{GW}$ (mean) stem from industry and commerce, comparable to the $6 \mathrm{GW}$ assumed in the German Grid Development Plan Scenario 2030c (Netzentwicklungsplan 2030c, NEP2030c) [12]. However, the operational state of assets are not taken into account, only simultaneity factors [39] or residual load curves [40]. For example, situations when the instantaneous power output of renewables is curtailed to values below the available supply are not endogenously modeled. This way, a source of upward flexibility, which is available by revoking curtailments, is not quantified. In [29] estimations are made how much flexibility of which inertia will be used in dependence of RESpenetration in the energy system.

From a modeling-type view, a number of works [13], [41]-[45] use energy system models similar to the one presented here but apply them in a different context such as modeling transformation paths to systems with reduced climate gas emissions. To our knowledge, no work has been done to analyze the flexibility potentials in a system model, especially not in corrective system operation.

This paper is structured as follows. In section 2, we describe the modeling method to obtain operation schedules and the utilization of the transmission corridors using an energy system model. Section 3 describes the calculation of the flexibility potentials derived from these operation schedules. The results are presented and discussed in sections 4 and 5 .

\section{Materials and Methods}

Flexibility of an energy resource is its ability to deviate from its uninfluenced power feed-in or uninfluenced load upon request. The energy resource offers to increase or decrease its load 
between an upper and a lower bound upon receiving a control communication. By offering flexibility, it will communicate a reference feedin profile together with available upwards and downwards deviation from the reference profile. If flexibility is used to increase the generation-to-load ratio, i.e., to increase feed-in or to decrease a load, its maximum deviation from the original schedule is called $\Delta \hat{P}_{x, t}^{u p}$, and $\Delta \hat{P}_{x, t}^{\text {down }}$ for the opposite case. Here, $x$ denotes the region and $t$ the timesteps at which the flexibility is available. This maximum deviation is seen as the upward or downward flexibility potential of said resource.

To determine flexibility, we use an energy system model for the geographical area of Germany in its 38 NUTS2 regions and its 12 gridneighbors: Poland, Czech-Republic, Austria, Switzerland, France, Luxembourg, Belgium, Netherlands, Great Britain, Denmark, Norway, and Sweden.

All generation and grid capacities (see Table 1) are taken from the InnoSys 2030 scenario, which is based on the NEP2030c (2019) [12] scenario. Modifications to the NEP2030c scenario in respect to the InnoSys scenario include a larger number of E-cars (10 million) and a shift of $1 \mathrm{GW}$ offshore wind power from the North-sea to the Baltic sea [12]. Installed capacities for neighboring countries are taken from a previous non-public study by Siemens and RWTH Aachen based on the "Ten Year Network Development Plan" (TYNDP) 2018 by the ENTSO-E and the Midterm Adequacy Forecast [46], [47].

The level of modeling detail is higher for German regions than for the neighboring ones, since the focus here lies on flexibility options for Germany. In the electricity sector, generators and loads are explicitly modelled for all regions, but optimization of sector-coupling elements is only performed in the German regions. Electrical heating, for example, is modeled exogenously as a fixed electricity demand for the neighboring states. The heat-sector, including decentral, central, and district-heating, is only explicitly considered in the German regions. The mobility and transport sector is not explicitly modelled, but its electrified parts, e.g., from electric vehicles and trains, are incorporated into a non-controllable electric load-curve. With all capacities except heatgeneration fixed, the models' investment and operation optimization reduces to an economic dispatch problem, where results are operation schedules (dispatches) for power generation $\bar{P}_{c}{ }^{\text {disp }}$ and loads $\bar{L}_{c}{ }^{\text {disp }}$, where $\bar{P}_{c}$ and $\overline{L_{c}}$ are matrices with dimensions $x \times t$, with $x$ regions and $t$ timesteps for each technology $c$.

All regions are modelled as single busses, i.e., assuming unobstructed intra-region exchange of heat and electricity. Choosing a regional resolution at the NUTS2-level, i.e., at a spatial scale of approximately $100 \mathrm{~km}$, is a compromise between the availability of data, computing demands and modelling accuracy. This resolution is expected to yield a sufficiently accurate representation on the spatial scale relevant for modeling power transmission [48]. The same resolution is chosen in [41]. Between regions, power exchange is performed via transmission corridors that represent the summed transmission capacities of real powerlines [49]. This approach is often used and yields sufficiently accurate results [50]. The power exchanged via these corridors between a region $x$ and $x^{\prime}$ is subject to optimization by the overall energy system model, effectively reproducing the behavior of optimally controlled HVDC lines, including a linear model for transmission losses. The total transfer capacities (TTCS) of these corridors are calculated based on data of a reference transmission grid model provided by the German TSOs. Several studies follow this approach [41], [43], [51]. Assuming preventive n-1-safe operation, these studies reduce the TTCs by $30 \%$ to obtain the resulting net transfer capacities (NTCs) [41]. Here, corrective operation is assumed. Therefore, NTCs are set at 


\begin{tabular}{|l|l|l|}
\hline Technology & Sources for parameter & Installed Capacities in Germany [GW] \\
\hline Biomass & {$[53],[54]$} & 6 \\
\hline CHP & {$[12]$, different manufacturers } & 8.3 \\
\hline Gas SC & {$[54]$} & 9.5 \\
\hline Gas CC & {$[54]$} & 15.6 \\
\hline Gas ST & {$[12],[54]$} & 0.6 \\
\hline Gas engines & $\begin{array}{l}{[55], \text { Manufacturer, Non-public }} \\
\text { data }\end{array}$ & 0.35 \\
\hline Lignite & {$[12],[54],[56],[57],[58]$} & 9 \\
\hline Hard coal & {$[12],[54],[56],[57],[58]$} & 8 \\
\hline PV & {$[54],[58],[59]$} & 104.5 \\
\hline Wind-power onshore & {$[17],[58]$} & 86.5 \\
\hline Wind-power offshore & {$[17],[58]$} & 17 \\
\hline Nuclear & {$[58],[60]$} & 0 \\
\hline Decentral batteries & {$[54],[61]$} & 10.1 \\
\hline $\begin{array}{l}\text { Power-to-heat, Power- } \\
\text { to-methane, Power-to- } \\
\text { hydrogen }\end{array}$ & {$[62],[63],[64]$, Non-public data } & $16.1 / 0.6 / 2.4$ \\
\hline $\begin{array}{l}\text { Misc. (Waste, blast- } \\
\text { furnaces gas, run-of- } \\
\text { river, pumped hydro, } \\
\text { heating technologies) }\end{array}$ & $\begin{array}{l}\text { [54], [58], [65]-[67], project data, } \\
\text { Non-public data, manufacturer }\end{array}$ & \\
\hline $\begin{array}{l}\text { data } \\
\text { the same values as } 7 T \text {, NTs to neighboring }\end{array}$ & \\
\hline
\end{tabular}

the same values as TTCs. NTCs to neighboring countries were provided by TSOs based on the NEP2030c scenario.

Note that, as a limitation of the model considering only transmission of active power, no statements about redispatch due to voltage limits can be made. This approximation is taken as permitted, since voltage-based redispatch is only about $1 / 20^{\text {th }}$ of the total in means of energy [52]. Further, assuming a congestionfree gas grid no explicit gas transmission model is included in this work.

For renewables, availability curves are derived from generation time-series provided by the TSOs, representing the infeed of RES in the year 2030 based on the weather conditions in the year 2012. This meteorological year is also chosen for neighboring countries to consistently model international market interactions.

Demand timeseries for electricity are also taken district heating data stems from in-house data.

Sources for the data for efficiency, cost, and operation parameters of the modeled technologies are listed in Table 1.

Flexibility can stem from different sources, providing different types of use. In this work, only assets mainly located in sub-transmission and distribution grids are considered. Some of them can lower their generation power or increase their load, providing downward flexibility $\Delta P_{t}^{\text {down }}$ at times $t$, others offer flexibility in the opposite direction, meaning increasing their power or lower the load, here called upward flexibility $\Delta P_{t}^{u p}$. Example assets in this work are listed in Table 2. 
Table 2: Flexibility options considered in calculation of potential

\begin{tabular}{|l|l|}
\hline Upward flexibility $\Delta P_{t}^{u p}$ & Downward flexibility $\Delta P_{t}^{\text {down }}$ \\
\hline $\begin{array}{l}\text { Wind power generation increase of situationally } \\
\text { curtailed units }\end{array}$ & Wind power curtailment \\
\hline $\begin{array}{l}\text { PV power generation increase of situationally } \\
\text { curtailed units }\end{array}$ & PV power curtailment \\
\hline Power-to-heat curtailment & Power-to-heat increase \\
\hline Decentral PV-battery loading decrease & \\
\hline Decentral PV-batteries increase of output & \\
\hline
\end{tabular}

From the simulation of the scenario chosen for this work, all generation schedules and hourly availabilities for all technologies are known. This way, curtailments of renewables are included in the output of the simulation. Since renewable power sources, here wind-power and PV, exhibit much smaller inertia in power gradients, especially in comparison to conventional turbinebased power generation sources, they can be an excellent source for flexibility [30], [57]. Especially assets subject to the VDE-AR-N 4120 [68] connected to the high-voltage grids are required to provide steep gradients if needed (0.33 to $0.66 \% P_{\text {inst }}$ per second), in- or decreasing from or to full power in between 2.5 to 5 minutes. If curtailed, these renewables can be activated and constitute an option for upward flexibility. Other options are the curtailment of large power-to-heat systems, which are often already qualified for demand side management [63] or decentral PV batteries, if equipped for remote operation and aggregated in some form. Examples for the usage of decentral batteries in this way can already be found in business e.g. by Sonnen, Lichtblick, and Tesla [69]-[72].

Sources for downward flexibility are more straightforward, the curtailment of PV and wind-power is a standard measure to relieve bottlenecks in the grid [73], and power-to-heat to provide negative controlling power is a known business case with different firms providing turn-key solutions [64], [74]. Loading
PV-batteries from the grid is not chosen as a flexibility source, since it is a less common usecase due to grid-fees.

For corrective grid operation, flexibility calls must be followed speedy and reliably. RES as flexibility sources in the sub-transmission systems are promising candidates to fulfill this requirement since they are controlled by the DSO's SCADA system with low latency and no interaction with intermediate system operators is necessary negotiate setpoint changes.

To get voltage-level resolved flexibility values from our modeling output consisting of operating schedules, allocation factors $V_{c}$ are used. These determine the share of each technology $c$ connected to a grid-voltage level and is done with data taken from "EEG in Zahlen" [75]. This data lists all renewable capacities installed at each voltage level. Based on this data, our analysis assumes that in $\mathbf{2 0 3 0}$ about $40 \%$ of onshore wind-power is connected in the sub-transmission level and another $40 \%$ in the distribution level at medium voltage. For $\mathrm{PV}$, only about $7 \%$ are in the sub-transmission level and about $38 \%$ in the next-lower voltage level. Depending on the installed power and the age of the assets, they must fulfill strict requirements in terms of controllability and power-gradients, as mentioned above with the VDE-AR-N 4120 [68].

For electrical loads, a dataset similar to [75] is not publicly available. Allocation factors $V_{c}$ have 
to be approximated from other data, as loads of similar magnitude as generation capacities are connected in similar voltage levels. Typically, loads over $6 \mathrm{MW}$ are connected to the MV/HVlevel, loads over $15 \mathrm{MW}$ to the HV subtransmission level [76]. These are assets which are in the direct control range of the first orderDSO. Since power-to-heat is a very cheap technology in means of power and is already used as negative control power, it is assumed to be controllable in large parts by the first-order DSO.

Flexible loads in lower voltage levels, for example e-cars, resistive heaters, or heatpumps, are not considered here, since controllability is not assured. Also, reaction timescales are much higher, since several DSOs or even customers would be included in the process.

\section{Calculation}

In the potential analysis, we determine the available flexibility for each technology, region and time step and we determine the demand for this flexibility by approximately modeling when and where corrective measures are necessary.

Our analysis is divided in two steps. We first analyze the generally available flexibility potential at critical time steps. We then focus on the spatial distribution of the flexibility potentials and analyze the available flexibility potential for each transmission corridor between regions. The first step is carried out by ranking time steps according to the redispatch volumes and calculating the globally available flexibility at the most critical time steps. In the second step, a loss of transmission capacity is assumed for each time step. The resulting loss of transmitted power is compared to the available flexibility for this corridor. The last step gives an indication of the amount of saved conventional redispatch.

\subsection{Analysis of the globally available flexibility}

The global analysis of flexibility potential consists of three stages:

1. Regionally resolved scenario modeling: The first stage is a capacity optimization, modeling regionally resolved capacity addition and an analysis if given capacities are sufficient. All generation capacities and their regional distributions are saved for the next two optimization steps. Of course, only capacity additions not already fixed by the scenario are optimized.

2. Approximate market-operation model: In the second stage, the optimization is done without grid constraints, i.e., setting transmission losses to zero and relaxing transmission capacity restrictions for the transport of electricity. This modified optimization model approximates the merit-order based behavior of the electricity market in Germany. From this stage, results are the dispatched power $\bar{P}_{c}{ }^{d i s p}$ and loads $\bar{L}_{c}{ }^{\text {disp }}$.

3. Approximated redispatch analysis: an energy system model with the fixed capacities from stage 1 and with grid transmission constraints and transmission losses is optimized. This yields the (approximate) redispatched operation of all generation technologies. The results are also matrices $\bar{P}_{c}{ }^{\text {red }}$ and $\bar{L}_{c}{ }^{\text {red }}$ with the same dimensions. The operation schedules from stage 2 and 3 differ whenever a transmission constraint is active. To provide to the loads, a shift of the generation between regions and 
technologies takes place to still meet all demands. The shift $\vec{P}$ diff between unconstrained and constrained electricity transmission approximates the redispatch.

$$
\vec{P}^{\text {diff }}=\sum_{x} \sum_{c}\left|\bar{P}_{c}^{\text {disp }}-\bar{P}_{c}^{\text {red }}\right|
$$

where $\vec{P}^{d i f f}$ is a vector with dimension $t$.

Simulated hours when the grid is at its capacity limits are identified by large amounts of redispatch $\vec{P}$ diff . Note that single individual transmission links may still operate at their capacity limit despite $\vec{P}^{\text {diff }}$ being small, a situation analyzed in $\mathrm{Sec}$ 3.2. For further analysis, these timesteps are ranked by magnitude. For the top $10 \%$ of these timesteps, the available flexibility potential is analyzed.

The optimized generation profiles obtained from the energy system model include data of curtailed renewables. These curtailments can be due to grid constraints, i.e., the available power cannot be transmitted, or due an overcapacity, i.e., the power that can be generated exceeds the demand. In the considered scenario with 219GW renewable generation capacities (208GW wind-power and PV, 11GW biomass and hydro), the latter occurs frequently, especially around noon when the PV generation peaks on windy days. The feed-in power of curtailed renewables can be increased, thus, providing a source of upward flexibility.

All assets that are to be used for supplying flexibility $\Delta P$ are located physically in one place, in the case of our model, a region $x$, the flexibility is also bound to this region. Calculation of available upward flexibility potential from different technologies $c$ for each timestep $t$ then is:

$$
\Delta \hat{P}_{c, t}^{u p}=\sum_{x} \Delta \hat{P}_{x, t, c}^{u p} \times V_{c}
$$

As established earlier, $V_{c}$ is the share that is available by means of voltage level and communication. For example, this might be $V_{c}=$ 0.4 for wind-power, since about $40 \%$ of the wind-power is in the sub-transmission voltage level and are controllable by the DSO. For the downward flexibility potential $\Delta \hat{P}_{c, t}^{\text {down }}$ the procedure is the same. These technologyresolved flexibilities or their distributions, respectively, at macroscopically critical timesteps are then the result of the first approach.

\subsection{Analysis of the transmission- corridor-resolved flexibility}

In this section, we analyze the available flexibility potential for each transmission corridor. In contrast to the overall flexibility in Sec. 3.1 that is available at time steps with large redispatch amounts, this section focuses on modeling possible congestions for each transmission corridor and analyses the available flexibility in adjacent regions. In particular, the available upward flexibility in the receiving region, i.e., the ability to increase generation 'behind' a congestion is an important quantity that is considered here.

In the approach chosen here, a loss of $2 \mathrm{GW}$ of transmission power (corresponding to a failure of a $380 \mathrm{kV}$ line or an HVDC link) is simulated for every timestep $t$. As a result of the system optimization, we obtain the transmitted power $P_{x x^{\prime}, t}$ on the corridor between regions $x$ and $x^{\prime}$ at time $t$. The transmission capacity of the line is denoted by $P_{x, x^{\prime}}^{\max }$. We evaluate if the sudden loss of transmission capacity leads to a transmission capacity limit violation. Timesteps for which this is the case are defined to be critical. The set of these time steps, $T_{x, x^{\prime}}^{c r i t}$, is defined as:

$T_{x, x^{\prime}}^{c r i t}=\left\{t \mid P_{x x^{\prime}, t}>P_{x, x^{\prime}}^{\max }-2 \mathrm{GW} \wedge P_{x x^{\prime}, t}>\frac{1}{2} P_{x, x^{\prime}}^{\max }\right\}^{\prime}$ 
The dropped power $P_{x x^{\prime}, t}^{d r o p}$ that needs to be compensated to return to a safe state within the (reduced) transmission capacity limits is calculated as

$P_{x x^{\prime}, t}^{d r o p}=\min \left(\max \left(P_{x x^{\prime}, t}-\left(P_{x, x^{\prime}}^{\max }-2 G W\right), 0\right), P_{x x^{\prime}, t}\right)$.

In corrective $\mathrm{n}-1$ operation, this power $P_{x x^{\prime}, t}^{d r o p}$ must be reliably compensated before triggering a cascading failure. To compensate it, we want to determine the upward flexibility potential per region on the receiving side $\left(x^{\prime}\right)$ and the downward flexibility potential on the sending side $(x)$ of the corridor:

$$
\Delta \hat{P}_{x, t}^{u p}=\sum_{c} \Delta \hat{P}_{x, t, c}^{u p} \times V_{c}
$$

For each pair of regions $x$ and $x^{\prime}$ on two sides of a corridor, the symmetrized flexibility potential $\Delta \hat{P}_{x x^{\prime}, t}^{*}$ is then defined as

$$
\Delta \hat{P}_{x x^{\prime}, t}^{*}=\min \left(\Delta \hat{P}_{x^{\prime}, t}^{u p}, \Delta \hat{P}_{x, t}^{\text {down }}\right)
$$

In this case, the power flow is from region $x$ to region $x^{\prime}$, therefore the upward flexibility is needed in region $x^{\prime}$ to resolve possible line failures in the corridor between the two regions. In most cases, curtailing power generation is easier than increasing it, therefore the $\Delta \hat{P}_{x^{\prime}, t}^{u p}$ is of greater interest in the scope of this work. Since in this work the focus lies on flexibility from underlying grids, flexible assets of sender and receiver regions and their non-mutual neighbors are considered. This is done because distribution grids often span over several gridconnection points or, in this case, regions. Also, in a contingency situation, a TSO would try to get flexibility from several sources to lower the risk of one not being able to deliver flexibility as planned.

With knowledge of flexible assets and their symmetrized flexibility potential $\Delta \hat{P}_{x x^{\prime}, t}^{*}$ the share of $P_{x x^{\prime}, t}^{d r o p}$ that can be compensated by this asset can be calculated:

$$
\Delta P_{x x^{\prime}, t}^{c o m p}=\min \left(P_{x x^{\prime}, t}^{d r o p}, \Delta \hat{P}_{x x^{\prime}, t}^{*}\right)
$$

We call this variable $\Delta P_{x x^{\prime}, t}^{\operatorname{comp}}$ correctively compensated power per corridor $x x^{\prime}$ and time $t$, since the power is only compensated in case of an equipment failure, not preventively in normal operation.

Since different technologies are more or less easily integrated into corrective system operation, different selections of technologies $c$ are included into calculation of the upward flexibility potential $\Delta \hat{P}_{x^{\prime}, t^{\prime}}^{u p}$, depending on the analysis (see Table 2 and Table 4).

To be able to analyze the importance of $\Delta P_{x x^{\prime}, t}^{c o m p}$, time averages per corridor can be obtained by summing over all critical timesteps and dividing by their number:

$$
\left\langle\Delta P_{x x^{\prime}}^{c o m p}\right\rangle=\frac{\sum_{t \in T_{c r i t, x x^{\prime}}} \Delta P_{x x^{\prime}, t}^{c o m p}}{\left|T_{c r i t, x x^{\prime}}\right|}
$$

Also, total compensated energy per corridor $E_{x x^{\prime}}^{c o m p}$ and over all corridors $E^{\text {comp }}$ are calculated:

$$
\begin{gathered}
E_{x x^{\prime}}^{c o m p}=\sum_{t \in T_{c r i t, x x^{\prime}}} \Delta P_{x x^{\prime}, t}^{c o m p} \\
E^{c o m p}=\sum_{x x^{\prime}} E_{x x^{\prime}}^{c o m p}
\end{gathered}
$$

These quantities are not directly comparable to a redispatch measure by a system operator due to several reasons:

1. Redispatch measures by a TSO are chosen such that a single shift in generation solves as much of the congestion along a route as possible. For example, an offshore wind park is curtailed and a gas power-plant in southern Germany is dispatched to increase its generation proportional to the curtailment of the wind park. Compensated energies $E_{x x^{\prime}}^{c o m p}$ on the other hand are only compensated 
between two regions, not by a flow through several regions. Since powerflows that lead to a critical state on one corridor may also lead to the same on the next corridor downstream, a simple sum to obtain $E^{\operatorname{comp}}$ overestimates a redispatch in comparison with a classical one performed by a TSO.

2. The analysis considers aggregated transmission corridors between regions (see section 2) in contrast to single transmission lines. Sensitivities of loss of transmission capacity on one hand and flexibility measures on the other hand are not resolved onto single lines and therefore are not quantitatively comparable with redispatch measures.

3. Also, preventive redispatches are done based on a market outcome that is independent of the power-grid. Therefore, the redispatch needs to compensate for all power flows that exceed the grid limits in normal operation and in case of a n-1 contingency. The calculation of possibly compensated energies as described above is based on an optimized model, which does not violate grid constraints, since they are boundary conditions in the optimization. This makes it difficult to compare possibly compensated energies to redispatch amounts as defined by the Bundesnetzagentur in Germany [77].

To estimate how much energy can be saved nevertheless, we compare compensated energies to the energies the chosen flexibility options are not able to compensate. To do this, dropped energies are calculated per corridor $E_{x x^{\prime}}^{d r o p}$ and in total $E^{d r o p}$ :

$$
E_{x x^{\prime}}^{d r o p}=\sum_{t} P_{x x^{\prime}, t}^{d r o p}
$$

$$
E^{d r o p}=\sum_{x x^{\prime}} E_{x x^{\prime}}^{d r o p}
$$

With these energies, shares of possibly compensated energies per corridor $S_{x x^{\prime}}^{E}$ and in total $S^{E}$ can be calculated:

$$
\begin{gathered}
S_{x x^{\prime}}^{E}=\frac{E_{x x^{\prime}}^{c o m p}}{E_{x x^{\prime}}^{d r o p}} \\
S^{E}=\frac{E^{c o m p}}{E^{d r o p}}
\end{gathered}
$$

Alternatively, the share of timesteps where the evaluated flexibility option is sufficient to completely compensate a capacity loss is of interest:

$$
\Theta_{x x^{\prime}, t}=\left\{\begin{array}{c}
1 \text { if } \Delta P_{x x^{\prime}, t}^{c o m p} \geq P_{x x^{\prime}, t}^{d r o p} \\
0 \text { else }
\end{array}\right.
$$

Evaluating $\Theta_{x x^{\prime}, t}$ for all timesteps for each corridor yields a share of how often the capacity loss can be compensated:

$$
S_{x x^{\prime}}^{T}=\sum_{t \in T_{c r i t, x x^{\prime}}} \frac{\Theta_{x x^{\prime}, t}}{\left|T_{c r i t, x x^{\prime}}\right|}
$$

A single number characterizing the availability of flexibility at relevant time steps is the share of timesteps $S^{T}$, where the flexibility is enough to compensate a loss of $2 \mathrm{GW}$ in corrective $\mathrm{n}-1$ operation. To calculate $S^{T}$, the corridor-resolved share is summed up and divided by the number of links:

$$
S^{T}=\sum_{x x^{\prime}} \frac{S_{x x^{\prime}}^{T}}{\# \text { links }}
$$

\section{Results}

Results from the approaches outlined in Sec. 3.1 and 3.2 are discussed in this section. 


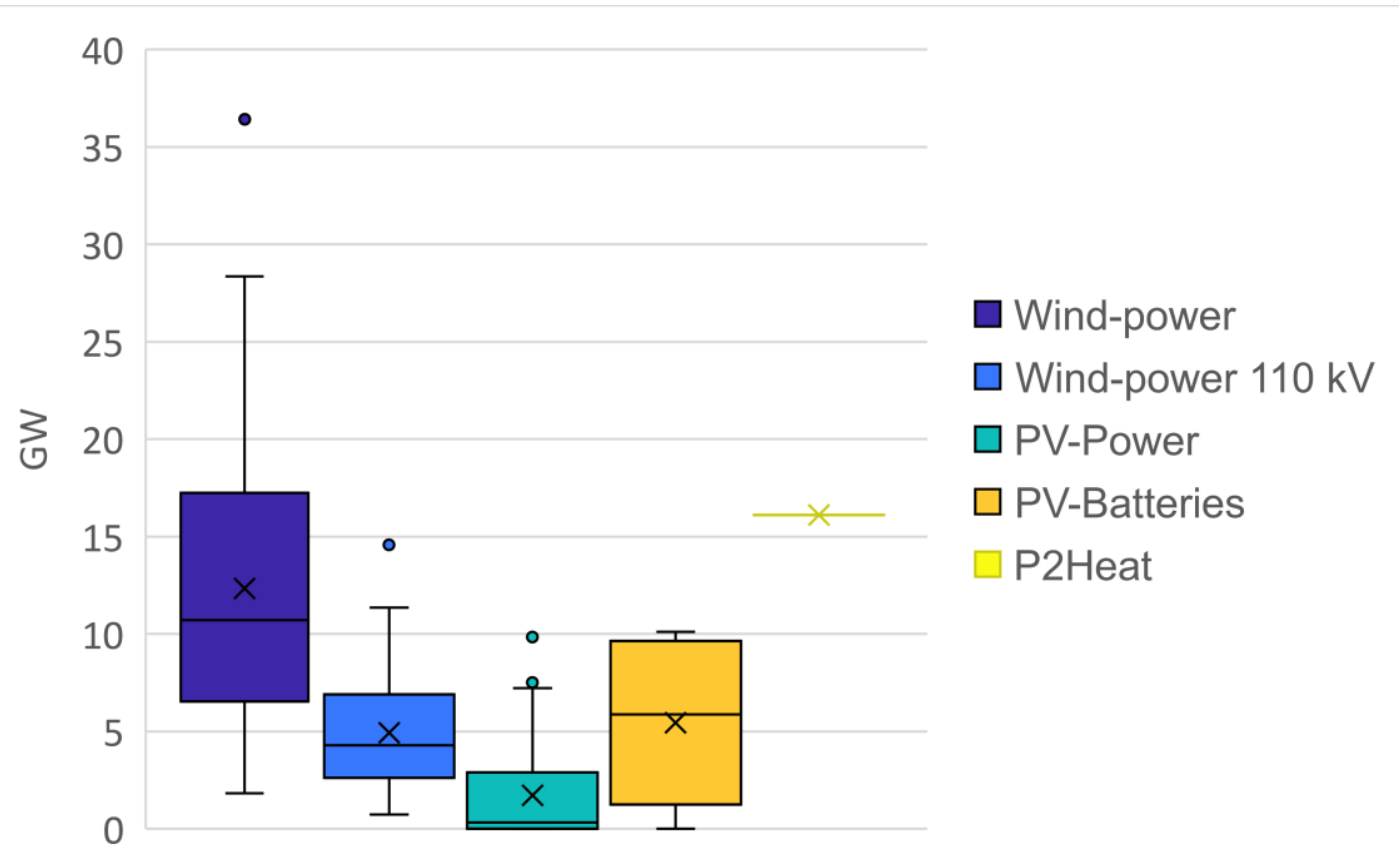

Figure 2: Box plots of upward flexibility $\triangle P^{u p}$ of different technologies, here curtailed RES (on-shore wind-power and PV-Power), electricity home-storage (PV-Batteries), and central power-to-heat plants (P2Heat). Wind-power in the sub-transmission $110 \mathrm{kV}$ grid is $40 \%$ of the total wind-power and assumed to be distributed proportional to the total wind-power. Crosses inside the boxes are means, whiskers are $1.5 *$ the inter-quartile range.

After sorting the vector $\vec{P}^{d i f f}$, the timesteps with the $10 \%$ highest values are taken, as they represent the $10 \%$ most critical simulated hours in the grid. For these timesteps, curtailments of renewables and other sources of flexibility are plotted in the box plot in Figure 2.

Figure 2 shows comparatively large amounts of curtailed wind-power, about $11 \mathrm{GW}$ in median and $12 \mathrm{GW}$ in mean. Even the share of wind parks in the sub-transmission level is on average curtailed by $5 \mathrm{GW}$ in the $10 \%$ most critical transmission scenarios. These parks are controlled by first order-DSOs (via IEC 60870-5104 transmission protocol) and can provide the curtailed power as upward flexibility. For comparison: the mean reduction of generation by redispatch caused by single overloads in 2017 was at about 450MW [2].

Noticeable is the power-to-heat flexibility of $16.1 \mathrm{GW}$ with small variance within the $10 \%$ critical time steps. In these time steps, typically, an excess of electricity is available leading to
$\mathrm{P} 2 \mathrm{H}$-plants operating at the maximum installed power. The little variance is, thus, caused by the coincidence of timesteps with large redispatch and timesteps with maximal $\mathrm{P} 2 \mathrm{H}$ operation.

Table 3: Different feed-in priorities by addition of marginal costs for RES

\begin{tabular}{|l|l|l|l|}
\hline $\begin{array}{l}\text { Marginal } \\
\text { costs } \\
€ / \text { kWh }\end{array}$ & $\begin{array}{l}\text { Equal } \\
\text { marginal } \\
\text { costs }\end{array}$ & $\begin{array}{l}\text { Wind- } \\
\text { power } \\
\text { prioritized }\end{array}$ & $\begin{array}{l}\text { PV } \\
\text { prioritized }\end{array}$ \\
\hline $\mathrm{PV}$ & 0 & 0.005 & 0 \\
\hline $\begin{array}{l}\text { Wind- } \\
\text { power }\end{array}$ & 0 & 0 & 0.005 \\
\hline
\end{tabular}

Small changes in the merit order were performed to test the robustness of how curtailments are distributed between PV and onshore wind power plants: Three sensitivities were analyzed, differing in variable operational costs for PV and wind-power given in Table 3. This change of generation from wind-power to PV or vice-versa is of interest, because a larger share of wind-power is installed in higher voltage-levels than PV [75]. Since higher voltage-levels mean stricter connection 
guidelines and better controllability by the DSO, wind-power is a better option for flexibility used to enable curative system operation.

Because both marginal costs are very small, it does not affect other technology options except for PV and wind-power. Nevertheless, this change has consequences for the regionally resolved operation schedules, since wind-power is more concentrated in northern regions of Germany, while PV is distributed more evenly.
In the base scenario a), neither PV nor windpower have marginal costs, in the second scenario b) only PV has marginal costs, and in scenario c) only wind-power has marginal costs. Changes in the flexibility results can be seen in Figure 3. In the scenario c) (operation costs for wind-power), there is almost no curtailment of PV at all while larger curtailments for windpower arise. In summary, these results are robust against changes of the merit order. Flexibility potentials of power-to-heat plants and PV-batteries do not change in these sensitivities and are not shown.

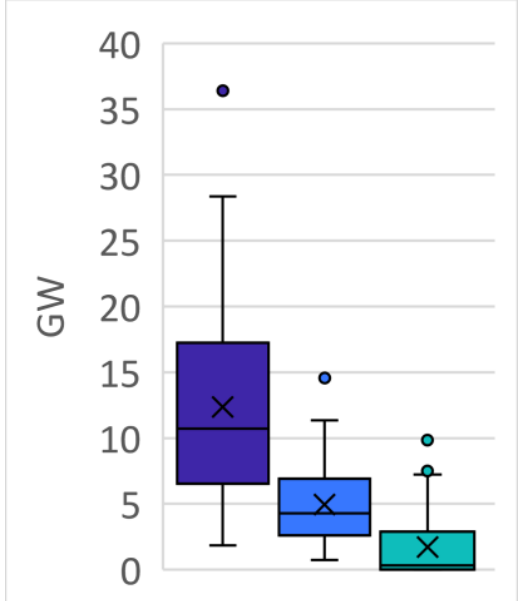

Standard merit order: PV- and windpower without marginal costs

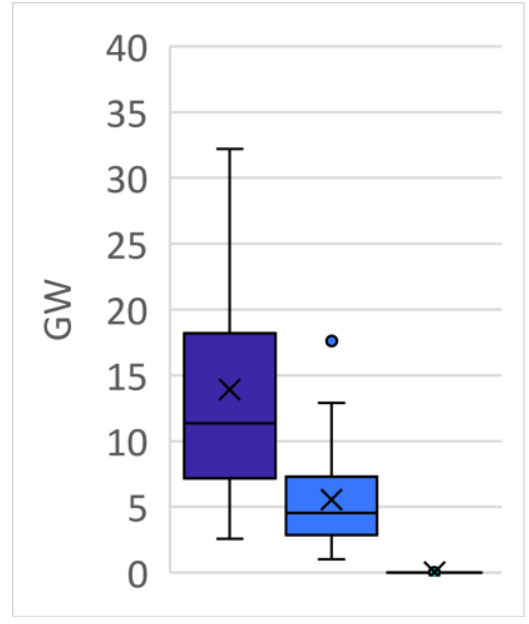

Wind-power with priority feed-in.

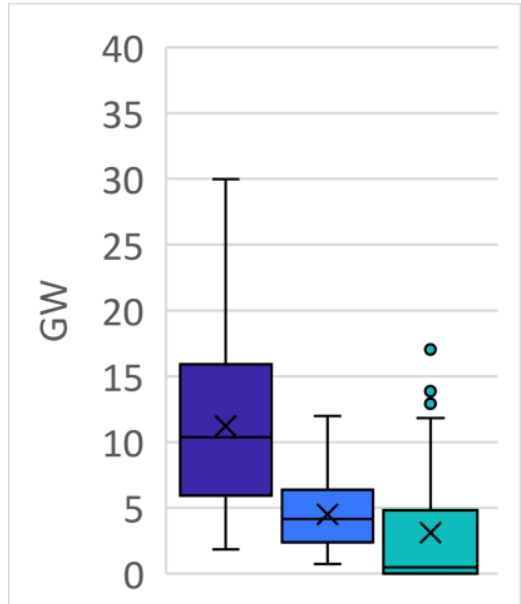

PV-power with priority feed-in

Figure 3: Potential of upward flexibility $\Delta P^{\wedge}$ up in different market regimes. Colors are the same as in Figure 2, meaning technologies shown are (from left to right) curtailed wind-power total and in sub-transmission grids, and curtailed PV. Other technologies are not shown, since they show no differences to the base case. Priority feed-in is modelled via extra marginal costs of $0.05 € / M W h$ on the competing technology

The second step of the analysis, as outlined in Sec. 3.2, focuses on the spatial distribution of the flexibility potentials. We consider individual transmission corridors and their connected regions. By probing how much transmitted power would be lost by a contingency in a transmission corridor, this method quantifies whether flexibility is simultaneously available and needed in each region. We evaluate flexibility in terms of the share of energy $S_{x x}^{E}$ of the dropped transmitted energy that can be compensated (see section 3.2) and in terms of 

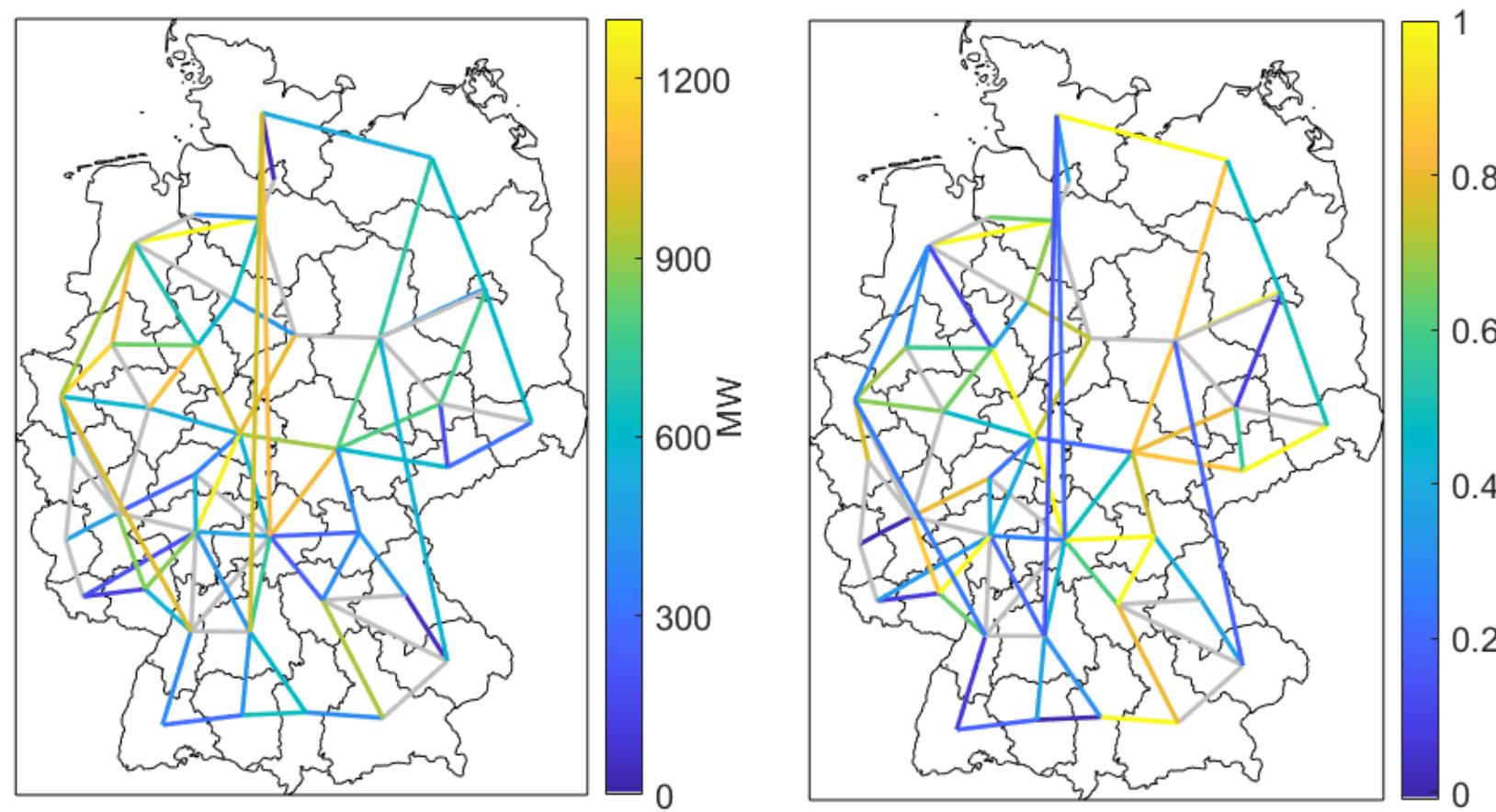

Figure 4: Maps showing the potential of wind-power and power-to-heat as technology options for flexibility. Grey corridors never reach critical states during the simulation.

Left: Map of average compensated powers per corridor $\left\langle\Delta P_{x x^{\prime}, t}^{\operatorname{comp}}\right\rangle$ by power-to-heat and wind-power.

Right: Map of the mean share of compensated energy per corridor $S_{x x \text {, }}^{E}$ for wind-power and power-to-heat

never reach critical states during the simulation.

mean compensated powers per corridor $\left\langle\Delta \mathrm{P}_{\mathrm{xx}, \mathrm{t}}^{\mathrm{comp}}\right\rangle$.

Figure 4 shows these results as a map of $S_{x x \prime}^{E}$ and $\left\langle\Delta P_{x x^{\prime}}^{c o m p}\right\rangle$. To calculate these quantities, upward flexibility $\Delta P_{x^{\prime}, t}^{u p}$ only from central power-to-heat plants and curtailed wind-power are considered, but all flexibility options found in Table 2 are taken into account for downward flexibility $\Delta P_{x, t}^{\text {down }}$.

As can be seen, flexibility potentials are not distributed homogeneously due to the inhomogeneous distribution of assets and their different operational states. Several corridors show appreciable flexibility. For example, in the most north-eastern corridor between Mecklenburg-Vorpommern and SchleswigHolstein, all energy can be compensated, $S_{x x x^{\prime}}^{E}=$ 1 , with a mean compensated power $\left\langle\Delta \mathrm{P}_{\mathrm{xx}^{\prime}, \mathrm{t}}^{\mathrm{comp}}\right\rangle$ of $772 \mathrm{MW}$. Overall, out of 84 corridors (with 19 never reaching critical states), 33 have a $50 \%$ share of compensated energy or more. Eighteen corridors have $80 \%$ share of compensated energy or more and for 9 of them transmission capacity losses of $2 \mathrm{GW}$ can be compensated completely $\left(S_{x x \prime}^{E}=100 \%\right)$.

Comparing both maps, one finds that large mean compensated power $\left\langle\Delta \mathrm{P}_{\mathrm{xx}^{\prime}, \mathrm{t}}^{\mathrm{comp}}\right\rangle$ does not necessarily correlate with high shares of compensated energy $S_{x x}^{E}$. This is especially true for the HVDC-connections, which have very high utilization at their maximum capacity.

Therefore, in most cases only a part of a possible capacity loss can be compensated.

The technology-combination of power-to-heat + wind is a promising candidate for corrective system operation, since both technologies provide large flexibility potentials and are, in terms of installed capacity, mostly connected to the sub-transmission grids. Due to their 
connection in higher-voltage-levels and due to large individual plant sizes (in comparison with e.g. PV-panels), power-to-heat and wind power plants typically are equipped with high-level communication interfaces, e.g. IEC 608706/TASE.2, enabling a reliable integration into a coordinated system operation of TSO and DSOs.

Results for compensated energies $S^{E}$ and $S^{T}$ (see 3.2) of different technology options are given in Table 4. Among single technology choices, power-to-heat yields the largest share of compensated energies, $S^{E}=49 \%$. An interpretation for this high value is as follows: In time steps with large renewable feed-in, especially wind power in the northern regions, low electricity prices and, simultaneously, large power transports in the transmission system occur. This leads to a high correlation between critical grid states and large power consumption of the $\mathrm{P} 2 \mathrm{H}$ plants in these time steps as it is optimal for $\mathrm{P} 2 \mathrm{H}$ plants to utilize cheap renewable supply. This interpretation indicates that large flexibility potentials would also be present in the absence of $\mathrm{P} 2 \mathrm{H}$ installations, namely, in this case, coming from curtailed renewables whose supply could not be used by $\mathrm{P} 2 \mathrm{H}$.

Table 4: Overview over shares of possibly compensated energies $S^{E}$ and share of timesteps $S^{T}$ when chosen flexibility options are enough to completely compensate the transmission capacity loss of 2GW. All flexibility options are used for $\Delta P_{x, t}^{\text {down }}$.

\begin{tabular}{|l|l|l|}
\hline $\begin{array}{l}\text { Technologies } \\
\text { used for } \Delta P_{x^{\prime}, t}^{u p}\end{array}$ & $S^{E}$ & $S^{T}$ \\
\hline $\begin{array}{l}\text { Curtailed wind- } \\
\text { power }\end{array}$ & 0.05 & 0.16 \\
\hline PV Batteries & 0.28 & 0.25 \\
\hline Power-to-heat & 0.49 & 0.36 \\
\hline $\begin{array}{l}\text { Wind-power and } \\
\text { power-to-heat }\end{array}$ & 0.50 & 0.40 \\
\hline All together & 0.64 & 0.58 \\
\hline
\end{tabular}

Note that in Sec 3.1, when evaluating the upward flexibility potential for wind power and
$\mathrm{P} 2 \mathrm{H}$ globally (in critical time steps) we found large values for both, wind and $\mathrm{P} 2 \mathrm{H}$, with a median of $11 \mathrm{GW}$ and $16.1 \mathrm{GW}$, respectively. In contrast, in the spatially resolved analysis, shown in Table 4, we find different orders of magnitude for wind, $S^{E}=0.05$, and $\mathrm{P} 2 \mathrm{H}, S^{E}=$ 0.49 . This finding emphasizes the importance of analyzing flexibility potentials individually for each transmission corridor.

For all technologies except curtailed windpower, the share of compensated energy $S^{E}$ is higher than the share of timesteps $S^{T}$ when transmission capacity loss could be compensated completely. This makes sense, since at many timesteps only a part of the energy can be compensated. This can be seen very well in Figure 4 on both central HVDC links (i.e. model representation of 'Suedlink"), where on average over one GW can be compensated. However, this measure only compensated transmission capacity losses completely in less than $20 \%$ of all observed timesteps. The reason why the ratio of $S^{E} / S^{T}$ is inverse for curtailed wind-power in comparison with other sources of flexibility, is that they influence different corridors than the other technologies, being able to compensate small amounts of power often, but not if a lot of power is needed.

So far, we have derived flexibility potentials from operation schedules of the different technologies. To analyze how, in practice, the utility of flexibility depends on to what share of a technology is integrated in a corrective system operation, we follow this up with a sensitivity analysis. We investigate how sensitive the resulting $S^{T}$ are to the share $V_{c}$ of them being connected to sub-transmission grids and used for flexibility provision. 


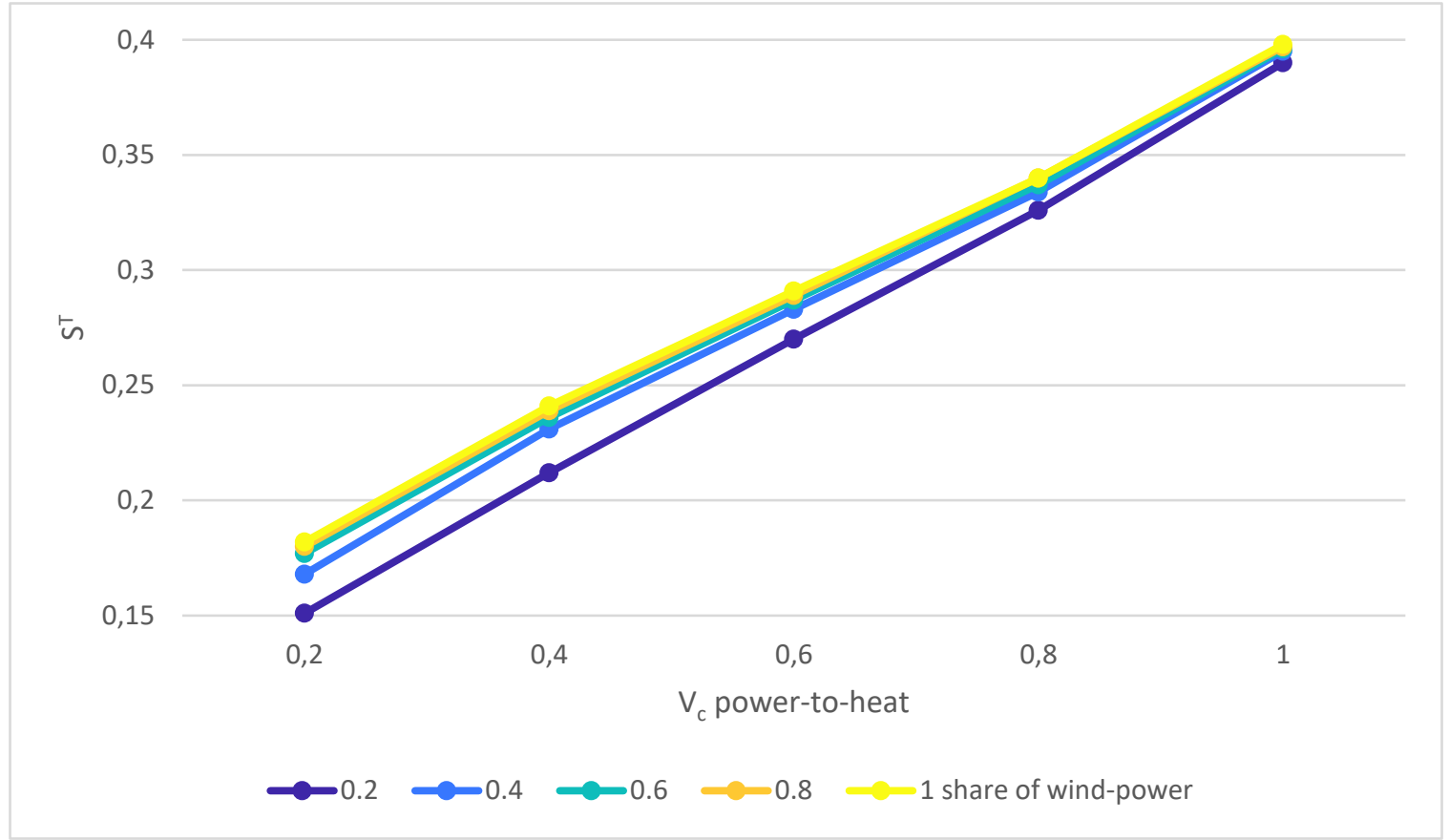

Figure 5: Influence of different allocation factors $V_{c}$ of wind-power (5 colors) and power-to-heat (horizontal axis) on completely compensable timesteps $S^{\wedge} T$

Results in Figure 5 show that the contributions of power-to-heat are significant in resolving as many transmission corridor losses as possible. Also, even for small shares $V_{c}$, significant $S^{T}$ can be reached for the transmission grid. Shares $V_{c}$ of wind-power only have an impact for smaller $V_{c}$ of power-to-heat.

In summary, these results show that flexibility from energy resources in the sub-transmission systems can provide substantial contributions to an efficient transmission system operation.

\section{Discussion}

Results of this study show, that flexibility is present at necessary times and locations. In both approaches to quantify flexibility and identifying critical timesteps, we find significant flexibility potentials, that can be used to enable a corrective operation of the transmission grid. Especially power-to-heat plants show substantial flexibility potentials and a large utility for a corrective systems operation, since power-to-heat operation is correlated with high transmission needs and high renewable electricity generation. However, we also show that a Germany-wide approach to estimating flexibility significantly overestimates the real value of curtailed renewables for the grid when not comparing them to individual flexibility demands in transmission corridors with high utilization. This stresses the need for a spatially resolved approach like the corridor-resolved calculation proposed in this work. This also holds when evaluating additional flexibility potentials of e.g. demand-side management in industry or households.

In the following, we would like to comment about the modeling approach chosen in this paper and make transparent possible limitations of this study that can be explored further in subsequent work:

- A gas transmission network was not endogenously modeled assuming that congestions in the gas grid occur much less frequently than for the power transmission system. A more detailed modeling of the interaction of gas and 
electricity transport, e.g., as in [41], [78], was out of the scope of this paper, but is, as an outlook, a likely extension which would allow one to calculate flexibility potentials of power-to-gas plants. Total electricity output from gas power plants obtained in our model is 70TWh, which is similar to the year 2008 when there were already $67 \mathrm{TWh}$ of electricity produced from natural gas [79], therefore the gas-grid in place is assumed to be sufficient.

- A quantitative correspondence of avoided conventional redispatch as obtained in redispatch simulations with detailed power grid models and the compensated energies in this work is not possible due to the different modeling approaches (see section 3.2). However, qualitative insights, such as the relevance of $\mathrm{P} 2 \mathrm{H}$ and curtailed renewables, are expected to be reproduced in a detailed redispatch simulation.

- The analysis of compensated energies $S^{E}$ is done assuming NTCs of a grid that is operated in a corrective $n-1$ mode, assuming a maximum of $100 \%$ utilization of the transfer capacities. In the present approach, this assumption is justified ex-post if the flexibility potential is enough to compensate for transmission capacity loss, i.e. $\Theta_{x x^{\prime}, t}=$ 1 (See 3.2). In cases when this is not true, preventive measures must be calculated in an integrated preventive and corrective mode (which is not included in the model).

- As an additional outlook, the transmission-corridor-resolved potential analysis can also be used to identify suitable regions for so-called grid-boosters, single-purpose grid-scale electrical storage systems for corrective measures. By ranking transmission corridors by compensated energies optimal grid-booster placements and sizes can be determined.

- In our model, power from biomass was not modelled as a flexible source, but with constant power-output. If flexibility from biomass plants is allowed, it is probable that even larger flexibility potentials will emerge.

- The total amount of curtailed RES depends on the assumptions in the model, e.g. operational constraints of lignite power-plants or other conventional plants with reduced flexibility. Even though availabilities of RES are the same in this model as in the NEP2030c, curtailments can differ. Of course, these curtailed energies in turn influence power flows and availabilities of flexibility. However, in a market with many RES and therefore many hours of low electricity prices, flexible loads of some sort will emerge. To efficiently integrate them for corrective grid operation and use their potential is imperative for a future energy system and part of the goals of the InnoSys2030 research project.

- In addition to power-to-heat, wind, and solar power analyzed in this study, demand-side management, e. g. for households, may provide flexibility for curative system operation. However, integrating households into a largescale DSM-system requires the development and test of new types of flexibility platforms. The complexity and time delays of integrating power-toheat, wind, and solar power are expected to be smaller because these plants are integrated into the present SCADA systems. Here, we analyzed the global flexibility potential and a spatially resolved flexibility measure, the correlation of flexibility at each 
corridor with critical states of this corridor. An analogous, spatially resolved analysis would be required to properly estimate the value for grid operation. Due to the high amounts in the scenario and other works, as stated in the introduction, the potential could be substantial.

From a regulatory standpoint, TSOs and DSOs must be able to override market-formed schedules in both directions to provide downward and especially upward flexibility. Today, only decreasing feed-in of renewables is practiced and intended by legislation [80]. This is also caused by the fact, that renewable power production is prioritized and normally RES are not operated in a curtailed mode. With developments towards an integrative redispatch regime, redispatch 2.0, and on the path towards a strongly renewable energy system, this will likely change [81].

\section{Conclusions}

To our knowledge, the present study is the first analysis of flexibility potential from subtransmission systems with an integrated model for a corrective transmission grid operation. Due to the shift from a supply-dominated to a demand-dominated operation of RES in the year 2030, large flexibility potentials were found. This potential was found to be available for critical grid use cases and in regions adjacent to stressed transmission corridors. It was found that this flexibility can substantially contribute to compensating transmission capacity lost in contingencies. In about $58 \%$ of all timesteps with critical corridor loadings, flexibility from RES and power-to-heat enable corrective grid operation without additional measures. Of the flexibility sources investigated, power-to-heat has shown to contribute most to compensated powers, because, due to its low costs, is has large installed capacities and uses cheap power from renewable energy sources.
These high capacities are an ideal source for flexibility due to their fast reaction times and existing communication interfaces to grid operators, which are already used for negative balancing power. Future analysis can further localize this potential within a more detailed grid model. Also, regulations need to be adapted to allow TSOs and DSOs to increase power generation of curtailed renewables and to integrate flexibility into a coordinated system operation.

\section{Acknowledgments}

We thank Marcus Lässig (MITNETZ STROM), Christian Lakenbrink (Netze BW), Julian Vielemeyer (Avacon), Mitra Ariatabar (TenneT), and Andreas Roehder (Amprion) both for their valuable feedback, discussion, and ideas in regard to our work as well as their direct help in form of data provisioning in the InnoSys 2030 consortium.

This research supported by the Bundesministerium für Wirtschaft und Energie (German Ministry for Economic Affairs and Energy) in the research project "Innovationen in der Systemführung bis 2030 (InnoSys2030)“ (FKZ: 0350036). It does not necessarily represent the opinion of all partners in the InnoSys 2030 consortium.

\section{References}

[1] "TYNDP 2018 Executive Summary: Connecting Europe: Electricity, 2025 2030 - 2040 Final version after consultation and ACER opinion," Avenue de Cortenbergh 100, 1000 Brussels, Belgium, Oct. 2019. [Online]. Available: https://tyndp.entsoe.eu/Documents/TYND P\%20documents/TYNDP2018/consultation /Main\%20Report/TYNDP2018_Executive\% 20Report.pdf.

[2] Bundesnetzagentur für Elektrizität, Gas, Telekommunikation, Post und Eisenbahnen, "Quartalsbericht zu Netz- 
und Systemsicherheitsmaßnahmen Gesamtjahr und Viertes Quartal 2017." Bundesnetzagentur für Elektrizität, Gas, Telekommunikation, Post und Eisenbahnen, Accessed: Mar. 20, 2019. [Online]. Available: https://www.bundesnetzagentur.de/DE/S achgebiete/ElektrizitaetundGas/Unterneh men_Institutionen/Versorgungssicherheit/ Netz_Systemsicherheit/Netz_Systemsicher heit.html.

[3] Katharina Kollenda, André Hoffrichter, Maximilian Schneider, Alexander Schrief, and Albert Moser, "Planungsorientierte Simulation kurativer Maßnahmen im Deutschen Übertragungsnetz," Graz, 2020.

[4] Tobias van Leeuwen, Ann-Kathrin Meinerzhagen, Andreas Roehder, and Stephan Raths, "Integration kurativer Maßnahmen in das Engpassmanagement im deutschen Übertragungsnetz," Graz, 2020.

[5] ENTSO-E, "Operational Security," ENTSO-E, P3, Mar. 2009. [Online]. Available:

https://www.entsoe.eu/fileadmin/user_u pload/_library/publications/entsoe/Opera tion_Handbook/Policy_3_Appendix_final.p df.

[6] NERC, "Reliability Standards for the Bulk Electric Systems of North America." NERCNorth American Electric Reliability Corporation, Jun. 23, 2020, Accessed: Jul. 20, 2020. [Online]. Available: https://www.nerc.com/pa/Stand/Pages/R eliabilityStandards.aspx.

[7] NERC, "Glossary of Terms Used in NERC Reliability Standards," Glossary, Jun. 2020. [Online]. Available: https://www.nerc.com/pa/Stand/Glossary \%20of\%20Terms/Glossary_of_Terms.pdf.

[8] Matthew H. Brown and Richard P. Sedano, Electricity Transmission, A Primer. National Council on Electric Policy, 2004.

[9] A. Schumacher, S. Fink, and K. Porter, "Moving Beyond Paralysis: How States and Regions Are Creating Innovative Transmission Projects; May 2009 - May 2010," NREL/SR-550-46691, 965985, Oct. 2009. doi: $10.2172 / 965985$.
[10] I. Chernyakhovskiy, T. Tian, J. McLaren, M. Miller, and N. Geller, "U.S. Laws and Regulations for Renewable Energy Grid Interconnections," NREL/TP--6A20-66724, 1326721, Sep. 2016. doi: $10.2172 / 1326721$.

[11] TenneT TSO GmbH, “InnoSys2030.” www.innosys2030.de.

[12] 50Hertz Transmission GmbH, Amprion $\mathrm{GmbH}$, TenneT TSO $\mathrm{GmbH}$, and TransnetBW GmbH, "SZENARIORAHMEN FÜR DIE NETZENTWICKLUNGSPLÄNE STROM 2030 - ENTWURF DER ÜBERTRAGUNGSNETZBETREIBER.” 2019, [Online]. Available: www.netzentwicklungsplan.de.

[13] S. Raths et al., "The Energy System Development Plan (ESDP)," presented at the International ETG Congress 2015, 2015.

[14] "EU-SySFlex." https://eu-sysflex.com/.

[15] "IMOWEN." http://forschungstromnetze.info/projekte/windparkcluster-sicher-ins-netz-integrieren/.

[16] "Interplan." https://interplan-project.eu/.

[17] Netze BW and TransnetBW GmbH, "DA/RE." https://www.dare-plattform.de/.

[18] "enera." https://projekt-enera.de/.

[19] Jonas Buhr et al., "Projektabschlussbericht - Bundesforschungsprojekt SysDL 2.0," Nov. 2018. Accessed: Apr. 27, 2020. [Online]. Available: https://www.sysdl20.de/ergebnisse/absch lu\%C3\%9Fbericht/.

[20] M. Duckheim et al., "Verbundprojekt 'REGEES': Optimale Betriebs- und Regelungsstrategien für das zuverlässige elektrische Energieversorgungssystem Deutschlands bei vollständiger Integration der Einspeisung aus erneuerbaren Energien im Zeithorizont 2030 : Schlussbericht REGEES," Fraunhofer IOSBAST, 2018. doi: 10.2314/KXP:1665338806.

[21] R. Schwerdfeger, D. Westermann Univ.Prof. Dr.-Ing., and F. Berger Univ.-Prof. Dr.Ing., "Vertikaler Netzbetrieb: ein Ansatz zur Koordination von Netzbetriebsinstanzen verschiedener 
Netzebenen," PhD Thesis, Universitätsverlag IImenau, IImenau, 2016.

[22] D. A. Contreras and K. Rudion, "Improved Assessment of the Flexibility Range of Distribution Grids Using Linear Optimization," in 2018 Power Systems Computation Conference (PSCC), Dublin, Ireland, Jun. 2018, pp. 1-7, doi: 10/gftskc.

[23] S. DIERKES et al., "Flex-Router-Konzept," Diskussionspapier. [Online]. Available: https://www.bdew.de/service/stellungnah men/diskussionspapier-flex-routerkonzept/.

[24] F. Capitanescu, "TSO-DSO interaction: Active distribution network power chart for TSO ancillary services provision," Electr. Power Syst. Res., vol. 163, pp. 226230, Oct. 2018, doi: 10/ggsr5p.

[25] D. Stock, F. Sala, A. Berizzi, and L. Hofmann, "Optimal Control of Wind Farms for Coordinated TSO-DSO Reactive Power Management," Energies, vol. 11, no. 1, p. 173, Jan. 2018, doi: 10/gc6pgz.

[26] D. Mayorga Gonzalez et al., "Determination of the Time-Dependent Flexibility of Active Distribution Networks to Control Their TSO-DSO Interconnection Power Flow," in 2018 Power Systems Computation Conference (PSCC), Dublin, Ireland, Jun. 2018, pp. 1-8, doi: 10.23919/PSCC. 2018.8442865.

[27] Joachim Gruber, Richard Tretter, and Matthias Wesseis, "Anreizmechanismen für die Bereitstellung von Flexibilität," EwMag., Jul. 2018, [Online]. Available: https://www.ewmagazin.de/anreizmechanismen-fuerbereitstellung-von-flexibilitaet/.

[28] Radecke, Julia, Hefele, Joseph, and Hirth, Lion, "Markets for Local Flexibility in Distribution Networks," Preprint, Accessed: Feb. 19, 2020. [Online]. Available: https://www.econstor.eu/handle/10419/2 04559.

[29] M. I. Alizadeh, M. Parsa Moghaddam, N. Amjady, P. Siano, and M. K. Sheikh-ElEslami, "Flexibility in future power systems with high renewable penetration: $A$ review," Renew. Sustain. Energy Rev., vol. 57, pp. 1186-1193, May 2016, doi: 10.1016/j.rser.2015.12.200.

[30] A. Jakhar, "A comprehensive review of power system flexibility," in 2017 IEEE International Conference on Power, Control, Signals and Instrumentation Engineering (ICPCSI), Chennai, Sep. 2017, pp. 1747-1752, doi: 10.1109/ICPCSI.2017.8392013.

[31] M. Zipf and D. Most, "Cooperation of TSO and DSO to provide ancillary services," in 2016 13th International Conference on the European Energy Market (EEM), Porto, Portugal, Jun. 2016, pp. 1-6, doi: 10.1109/EEM.2016.7521273.

[32] D. M. Gonzalez, L. Robitzky, S. Liemann, U. Hager, J. Myrzik, and C. Rehtanz, "Distribution network control scheme for power flow regulation at the interconnection point between transmission and distribution system," in 2016 IEEE Innovative Smart Grid Technologies - Asia (ISGT-Asia), Melbourne, Australia, Nov. 2016, pp. 2328, doi: 10.1109/ISGT-Asia.2016.7796355.

[33] M. Klobasa et al., "Lastmanagement als Beitrag zur Deckung des Spitzenlastbedarfs in Süddeutschland," Endbericht Einer Stud. Von Fraunhofer ISI Forschungsgesellschaft Für Energiewirtschaft Erstellt Im Auftr. Von Agora Energiewende, 2013.

[34] S. von Roon and T. Gobmaier, "Demand response in der industrie-status und potenziale in deutschland," Münch. Forschungsstelle Für Energiewirtschaft EV FfE, 2010.

[35] "Dena Netzstudie II: Integration of Renewable Energy Sources in the German Power Supply System from 2015 - 2020 with an Outlook to 2025," Deutsche Energie-Agentur GmbH (dena), 2012. [Online]. Available: https://www.dena.de/themenprojekte/projekte/energiesysteme/netzstu die-i-und-ii/.

[36] P. Elsner, B. Erlach, M. Fischedick, B. Lunz, and D. U. Sauer, Flexibilitätskonzepte für 
die Stromversorgung 2050: TechnologienSzenarien-Systemzusammenhänge. acatech, 2015.

[37] F. Adamek et al., "Energiespeicher für die Energiewende: Speicherungsbedarf und Auswirkungen auf das Übertragungsnetz für Szenarien bis 2050," VDE Verband Elektrotechnik Elektron. Informationstechnik EV Frankf. Am Main, 2012.

[38] Bundesnetzagentur für Elektrizität, Gas, Telekommunikation, Post und Eisenbahnen, "Marktstammdatenregister," Marktstammdatenregister, Apr. 22, 2020. https://www.marktstammdatenregister.d e/MaStR/ (accessed Apr. 22, 2020).

[39] V. der E. E. Informationstechnik eV, Demand Side IntegrationLastverschiebungspotenziale in Deutschland. VDE, Frankfurt am Main, Germany, 2012.

[40] N. Krzikalla, S. Achner, and S. Brühl, Möglichkeiten zum Ausgleich fluktuierender Einspeisungen aus Erneuerbaren Energien: Studie im Auftrag des Bundesverbandes Erneuerbare Energie. Ponte Press, 2013.

[41] Gasunie Deutschland and TenneT TSO GmbH, "Phase 2 - Pathways to 2050." Accessed: Feb. 19, 2020. [Online]. Available: https://www.tennet.eu/de/news/news/ga sunie-und-tennet-klimapolitische-zielelassen-sich-nur-mit-einem-integrierteneuropaeischen-energi/.

[42] P. Gerbert et al., Klimapfade für Deutschland. BCG, The Boston Consulting Group, 2018.

[43] Knorr, Kaspar et al., "Abschlussbericht des Forschungsprojektes Kombikraftwerk 2," Abschlussbericht, 2014. [Online]. Available: http://www.kombikraftwerk.de/mediathe k/abschlussbericht.html.

[44] Philip Sterchele et al., "Wege zu einem klimaneutralen Energiesystem: Die deutsche Energiewende im Kontext gesellschaftlicher Verhaltensweisen,"
Fraunhofer-Institut für Solare Energiesysteme ISE, Freiburg, Feb. 2020. Accessed: Feb. 27, 2020. [Online].

Available:

https://www.ise.fraunhofer.de/de/veroeff entlichungen/studien/wege-zu-einemklimaneutralen-energiesystem.html.

[45] Martin Robinius et al., "Kosteneffiziente und klimagerechte Transformationsstrategien für das deutsche Energiesystem bis zum Jahr 2050. (Kurzfassung)," INSTITUT FÜR TECHNO-ÖKONOMISCHE SYSTEMANALYSE (IEK-3), Forschungszentrum Jülich. Accessed: Apr. 27, 2020. [Online].

[46] ENTSO-E, "Ten Year Network Development Plan," 2018.

[47] ENTSO-E, "Midterm Adequacy Forecast," 2017.

[48] J. Horsch and T. Brown, "The role of spatial scale in joint optimisations of generation and transmission for European highly renewable scenarios," in 2017 14th International Conference on the European Energy Market (EEM), Dresden, Germany, Jun. 2017, pp. 1-7, doi: 10.1109/EEM.2017.7982024.

[49] C. Müller et al., "Modeling framework for planning and operation of multi-modal energy systems in the case of Germany," Appl. Energy, vol. 250, pp. 1132-1146, Sep. 2019, doi: 10/gf5p76.

[50] W. Biener and K. R. Garcia Rosas, "Grid reduction for energy system analysis," Electr. Power Syst. Res., vol. 185, p. 106349, Aug. 2020, doi: 10.1016/j.epsr.2020.106349.

[51] W. Zappa, M. Junginger, and M. van den Broek, "Is a $100 \%$ renewable European power system feasible by 2050?," Appl. Energy, vol. 233-234, pp. 1027-1050, Jan. 2019, doi: 10/gf8fz5.

[52] "Netztransparenz.de," Informationsplattform der deutschen Übertragungsnetzbetreiber. https://www.netztransparenz.de/EnWG/R edispatch.

[53] Simone Besgen, "Ergebnisse messtechnischer Untersuchungen an 
landwirtschaftlichen Biogasanlagen im Rheinland," Rheinischen FriedrichWilhelm-Universität zu Bonn.

[54] CHRISTOPH KOST, SHIVENES SHAMMUGAM, VERENA JÜLCH, HUYENTRAN NGUYEN, and THOMAS SCHLEGL, "Stromgestehungskosten erneuerbare Energien März 2018." FraunhoferInstitutfür Solare Energiesysteme ISE, Mar. 2018.

[55] eia - U.S. Energy Inforamtion Administration, "Capital Cost Estimates for Utility Scale Electricity Generating Plants." Nov. 2016, [Online]. Available: www.eia.gov.

[56] Mario Bachhiesl et al., "Stromerzeugung 2018|2019 - Zahlen und Fakten." VGB PowerTech e.V., Aug. 2018, [Online]. Available: www.vgb.org.

[57] Dimitri Pescia, "Flexibility in thermal power plants - With a focus on existing coal-fired power plants." Agora Energiewende, 2017, [Online]. Available: www.agora-energiewende.de.

[58] "Levelised Cost of Electricity LCOE 2015." VGB PowerTech Service GmbH Verlag technisch-wissenschaftlicher Schriften.

[59] E. Vartiainen, G. Masson, C. Breyer, D. Moser, and E. Román Medina, "Impact of weighted average cost of capital, capital expenditure, and other parameters on future utility-scale PV levelised cost of electricity," Prog. Photovolt. Res. Appl., p. pip.3189, Aug. 2019, doi: 10.1002/pip.3189.

[60] Thomas Geissmann, "Computation of the Levelized Cost of Electricity under Uncertainty and Endogeneities in Inputs," IAEE Energy Forum, no. 1/2017, pp. 15-18, 2017.

[61] Johannes Weniger, Selina Maier, Lena Kranz, Nico Orth, Nico Böhme, and Volker Quaschning, "Stromspeicher - Inspektion 2018." Hochschule für Technik und Wirtschaft (HTW) Berlin, Nov. 2018, [Online]. Available: www.stromspeicherinspektion.de.

[62] Manuela Bücken et al., "Potenziale der Sektorkupplung und Nutzung von Strom aus Erneuerbaren Energien im Wärmebereich in Sachsen-Anhalt." Landesamt für Umweltschutz SachsenAnhalt, Nov. 02, 2017.

[63] Thomas Estermann, Simon Pichlmaier, Andrej Guminski, and Christoph Pellinger, "Kurzstudie Power-to-X Ermittlung des Potenzials von PtX-Anwendungen für die Netzplanung der deutschen ÜNB." Forschungsstelle für Energiewirtschaft e.V., Nov. 2017, [Online]. Available: www.ffe.de.

[64] "Power-to-Heat zur Integration von ansonsten abgeregeltem Strom aus Erneuerbaren Energien Handlungsvorschläge basierend auf einer Analyse von Potenzialen und energiewirtschaftlichen Effekten." Agora Energiewende, Jun. 2014, [Online]. Available: www.agora-energiewende.de.

[65] Danish Energy Agency and Energinet, "Technology Data - Energy Plants for Electricity and District heating generation." Aug. 2016, [Online]. Available: http://www.ens.dk/teknologikatalog.

[66] RWE Power AG, "RWE Power - die ganze Kraft Kraftwerk Huckingen." RWE Power AG, [Online]. Available: www.rwe.com.

[67] Sabine Flamme, Jörg Hanewinkel, Peter Quicker, and Kathrin Weber, "Energieerzeugung aus Abfällen: Stand und Potenziale in Deutschland bis 2030." Umweltbundesamt, [Online]. Available: http://www.umweltbundesamt.de/publik ationen.

[68] "Technical Connection Rules for HighVoltage (VDE-AR-N 4120)." VDE VERLAG GMBH, Oct. 19, 2018, [Online]. Available: https://www.vde.com/en/fnn/topics/tech nical-connection-rules/tar-for-highvoltage.

[69] Dan van Holst Pellekaan, "South Australia helps keep the lights on in Queensland," Nov. 15, 2019.

https://web.archive.org/web/2019121422 3336/https://premier.sa.gov.au/news/sou th-australia-helps-keep-the-lights-on-inqueensland. 
[70] Government of South Australia, "South Australia's Virtual Power Plant: VIRTUAL POWER PLANT REACHES 1,100 HOMES." https://virtualpowerplant.sa.gov.au/.

[71] "Lichtblick Schwarmenergie." https://www.lichtblick.de/schwarmenergi e/schwarmbatterie/.

[72] "sonnenCommunity," Feb. 20, 2020. https://sonnengroup.com/sonnencommu nity/ (accessed Feb. 20, 2020).

[73] Bundesministerium der Justiz und Verbraucherschutz, Gesetz für den Ausbau erneuerbarer Energien (ErneuerbareEnergien-Gesetz - EEG 2017). 2017.

[74] "glood: Power to Heat Überschussstrom sinnvoll speichern." GLOOD GMBH POWER TO HEAT.

[75] Bundesnetzagentur, "EEG in Zahlen 2018." Accessed: Feb. 19, 2020. [Online].

Available: https://www.bundesnetzagentur.de/DE/S achgebiete/ElektrizitaetundGas/Unterneh men_Institutionen/ErneuerbareEnergien/Z ahlenDatenInformationen/zahlenunddate n-node.html.

[76] e.dis, Thüringer Energienetze, avacon, enso Netz, Mitnetz Strom, and WEMAG Netz GmbH, "Gemeinsamer Netzausbauplan der Arbeitsgemeinschaft der ostdeutschen 110-kVFlächennetzbetreiber 2017." [Online]. Available: https://www.arge-fnbost.de/arbeitsfelder/netzausbauplan.

[77] Bundesnetzagentur für Elektrizität, Gas, Telekommunikation, Post und Eisenbahnen, "Redispatch," Redispatch. https://www.bundesnetzagentur.de/DE/S achgebiete/ElektrizitaetundGas/Unterneh men_Institutionen/Versorgungssicherheit/ Engpassmanagement/Redispatch/redispat ch-node.html (accessed May 06, 2020).

[78] M. Robinius et al., Comparative Analysis of Infrastructures: Hydrogen Fueling and Electric Charging of Vehicles, vol. 408. Jülich: Forschungszentrum Jülich $\mathrm{GmbH}$ Zentralbibliothek, Verlag, 2018.

[79] Statistisches Bundesamt, GENESIS-Online Datenbank, Tabelle 33111-0001. 2015.
[80] Bundesministerium der Justiz und Verbraucherschutz, Netzausbaubeschleunigungsgesetz Übertragungsnetz. 2011.

[81] Dr. Sandu-Daniel Kopp, "Redispatch 2.0," BDEW. [Online]. Available: https://www.bdew.de/energie/redispatch $-20 /$. 